\title{
PATHWAY TO HOLISTIC CARE OF PSYCHIATRIC ILLNESS IN NATIONAL SERVICEMEN
} PRESENTING IN PRIMARY HEALTHCARE

Dr Lee Bing Long, Dr Jeffrey Jiang Song'En, Dr Soo Shuenn Chiang, Dr Tan Jian Hong

\begin{abstract}
We present a case study of a 22-year-old National Serviceman presenting with the main complaint of insomnia. This case demonstrates possible gaps in the integration of care between public and National Service healthcare. We illustrate a pathway that primary physicians may use to improve communication with National Service healthcare.
\end{abstract}

Keywords: Depression, generalised anxiety disorder, insomnia, psychiatric illness

\section{SFP2021; 47(3) :}

\section{CASE PRESENTATION}

"Doc, I can't seem to fall asleep. I'm turning up late, and I can't concentrate during my job, but nobody in camp seems to understand..."

$\mathrm{Mr} \mathrm{T}$ is a 22-year-old Chinese male managed under our care in the outpatient community clinic supported by the National University Hospital (NUH) Assessment \& Shared Care Team (ASCAT), where the primary physician is supervised by an ASCAT psychiatrist in the management of outpatient psychiatric medicine.

He was enlisted into National Service (NS) nine months ago and was deployed as logistics personnel. He had a past medical history of childhood asthma, pes planus and mild thoracic scoliosis. His parents have a strained relationship. Both his mother and sister have a history of depression. His genogram is illustrated in Figure 1.

\section{LEE BING LONG}

Family Medicine Resident

Family Medicine Programme

National University Hospital

\section{JIANG SONG'EN, JEFFREY}

Associate Consultant

St Luke's Hospital

\section{SOO SHUENN CHIANG}

Consultant

Department of Psychological Medicine

National University Hospital

\section{TAN JIAN HONG}

Department of Psychological Medicine

Institute of Mental Hospital

\section{Figure I: Genogram}

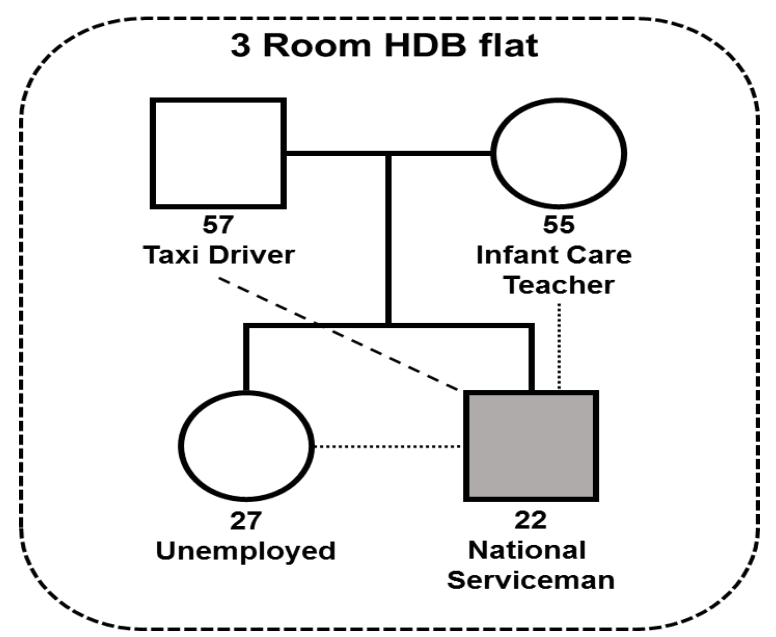

He was initially referred to our clinic from the emergency department (E.D.) for insomnia. He was also referred by the E.D. to the general medicine clinic due to his concerns of having Marfan's syndrome but was discharged as he did not fulfil the criteria, and there were no alarming signs.

During the past two months, $\mathrm{Mr} \mathrm{T}$ experienced increasing difficulty falling asleep daily and could only fall asleep at 3 am before waking up again at $6 \mathrm{am}$. He had been having the same problem for the past three years when he was schooling in the polytechnic. Mr T claimed that of late, this problem had been getting worse and was affecting his life more adversely. He had trouble initiating sleep, often lying in bed for hours trying to fall asleep. When he was unable to fall asleep, he would play handphone games into the early mornings. He felt that "there were a lot of things" in his head that kept him awake. He admitted that these "things" were his worries which kept remunerating in his mind, such as the fear of getting punished by his superiors for being late, which he recently experienced when he overslept. The worries had become a daily affair and had become more frequent over the past six months. In the past, while schooling, he would get stressed during the examination period to the point of having suicidal thoughts, though he had not made any attempts before. These would cease once the exam was over. Moreover, he had school counsellors who motivated him then.

At the point of the consult, even routine tasks caused him to worry to the point of getting tremors of his hands. When delegated a particular task by his superior, he would get anxious and was unable to concentrate because he was afraid he could not match up to the expectations demanded of him. He constantly feared new tasks such as learning to use weapons and drills as he felt he could not keep up with his peers. His current worry at the time of consult was having to go for live firing and outfield training. He had no thoughts 
of harming himself or others but was scared he could not follow the drills correctly. This made him restless and tired for the rest of the day and perpetuated his insomnia.

$\mathrm{MrT}$ perceived that he was underperforming in his vocation in NS, leading to feelings of guilt that his peers had to take on his tasks due to his failures. Many times, he felt sad as he could not relate to his NS peers and felt isolated. He had also lost interest in most of his usual hobbies except handphone games, which he used to pass the time when he was unable to fall asleep. This was also associated with reduced appetite, resulting in skipping meals and weight loss. He had unintentionally lost $3 \mathrm{~kg}$ over the past six months.

He did not consume caffeinated drinks, alcohol or illicit drugs. He denied any visual or auditory hallucinations. He smoked four sticks a day for ten years. He kept in touch with old friends by phone occasionally but has not met up with any of them since his NS started. He did not have much emotional support from his family, preferring not to share with troubles with them. $\mathrm{Mr} \mathrm{T}$ denied being in a relationship or being sexually active. Pre-morbidly, he described himself as having an anxious personality. He hopes to find employment after NS to be financially independent as he had failed to get into university.

On examination, his vital signs were normal. There were no signs of hyperthyroidism or scars. There was no Marfanoid feature. He had scoliosis and pes planus. The mental state examination revealed a kempt, quiet male lacking eye contact with teary eyes. His speech was relevant, and there were no psychotic symptoms or suicidal ideation. His GAD-7 score was 17 (severe anxiety), and his PHQ-9 score was 12 (moderate depression). His thyroid function test was normal.

Mr T was diagnosed with Generalised Anxiety Disorder (GAD) and depression. He was taught relaxation techniques and given smoking cessation advice. He was also encouraged to reduce nocturnal screen-time and increase daytime exercises to help with his insomnia. He was referred to the psychologist for cognitive behavioural therapy (CBT). His mother was also informed of his diagnosis with his permission to include his family in the treatment process. He was started on fluvoxamine $50 \mathrm{mg} \mathrm{ON}$. He was also given alprazolam $0.25 \mathrm{mg}$ ON/PRN due to the severity of insomnia which was distressing to him.

A memo was written to his camp medical officer to refer him to the NS counselling services and alert his camp superiors. He was also recommended not for live firing and strenuous activities during his treatment.

On review a month later, he informed me that he experienced side effects of nausea and bloating from fluvoxamine and had stopped taking it. His insomnia issue had improved, but he was still experiencing anxiety and depression affecting his sleep. Hence, he was switched to mirtazapine $15 \mathrm{mg} \mathrm{ON}$ for the sedative effects, and his alprazolam was stopped. Further, he had not seen his camp doctor as he was given an appointment date for a few weeks later. $\mathrm{He}$ was also experiencing difficulties attending psychologist appointment due to the distance from his camp. A phone call to the camp doctor was made to ensure that his superiors and the National Service psychiatric service branch knew his condition and recommendations for camp psychologist support.

In subsequent reviews, his symptoms of anxiety had improved (GAD-7 score 10), and he was less depressed (PHQ-9 score 6). He felt that his sleep difficulties had also improved, and he was kept on mirtazapine.

In view of his mental health condition, the camp doctor had also arranged for a medical board to review his Physical Employment Standards (PES) status for fitness to participate in National Service activities. He was connected to the camp psychologist by the camp doctor who continued to provide in-camp counselling. His journey through the healthcare system is summarised in Figure 2.

\section{Figure 2: Movement of patient transiting in the healthcare system}

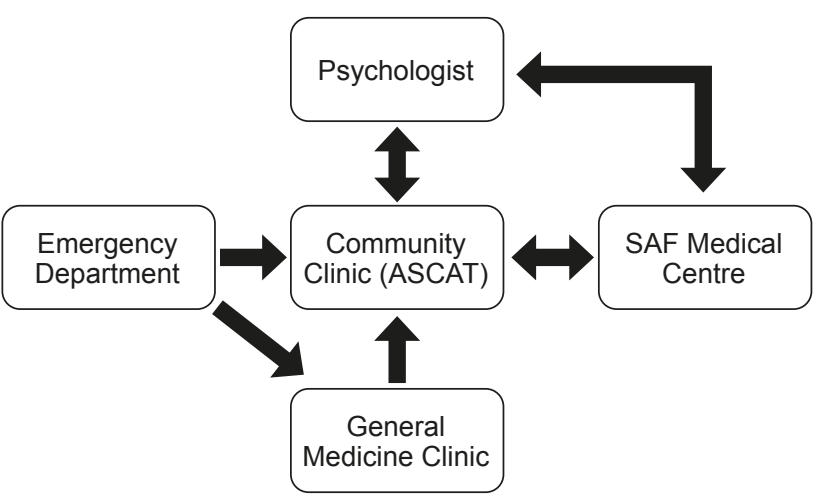

\section{PROBLEMS IDENTIFIED FOR PRIMARY PHYSICIANS}

\section{Diagnostic challenges when seeing National Servicemen with psychiatric disorders presenting outside of camp}

Primary healthcare physicians face difficulty diagnosing psychiatric disorders in National Servicemen. The NS population faces the stigmatisation of malingering symptoms, especially in cases of presentation with nonspecific symptoms. When treating this population, primary physicians often have to maintain the delicate balance of treating their symptoms seriously while being mindful of the possibility of secondary gains.

Due to the various National Service settings that these young adults are placed in, primary physicians also have to determine if the problems faced by their patients are due to temporary adjustment issues when placed in an unfamiliar setting or an onset of psychiatric disorder in early adulthood which may need specialist input. 


\section{Management of psychiatric disorders in National Servicemen require holistic care}

Compared to the general population, this patient group has to learn to handle firearms and work in a hierarchal system at a young age, which may create an overly stressful environment for some. Management of psychiatric disorders requires holistic management, and the environment is a contributing factor.

Primary physicians face a challenge during their treatment process if they do not know how to influence the patient's National Service setting in a purposeful way.

\section{Communication between both National Service and public healthcare and sharing of patient information pertinent to his care}

The approach to psychiatric patients in a National Service setting is unique as these patients are straddling between two separate healthcare systems - both public and National Service where healthcare records may not be fully shared or accessible.

Some physicians may not be familiar with the avenues through which they can communicate their prescribed therapy and medical advice to the patient's superiors. They may not be aware of all the National Service resources that can be utilised for the soldier's mental health.

\section{LITERATURE REVIEW}

\section{A. Management of patients with anxiety disorders and co-morbid depression, treatment of insomnia}

Psychiatric comorbidity showed a statistically significant increase from 2.5 percent to 3.5 percent in the local population. ${ }^{1}$ Presence of co-morbid depression with anxiety predicts a poorer outcome for treatment than having either disorder alone. ${ }^{2}$

Non-pharmacological treatment can be as effective as a pharmacological treatment in patients with co-morbid anxiety and depression, but more severely affected individuals like $\mathrm{Mr} \mathrm{T}$ tend to require medications. ${ }^{3}$

\section{Non-pharmacological treatment in $\mathrm{Mr}$ T' case}

Cognitive behavioural therapy (CBT) is the most commonly used treatment for both anxiety and depression. A simple psychological case formulation is useful to summarise descriptive information provided by the patient, formulate a hypothesis about the causes, precipitants and maintaining influences of his problems, and developing effective CBT treatments. An example using $\mathrm{Mr}$ T's case is provided in Table 1.
Table I: Case formulation for $\mathrm{Mr} \mathbf{T}$

\begin{tabular}{|c|c|c|c|}
\hline $\begin{array}{l}\text { Case } \\
\text { Formulation }\end{array}$ & Biological & Psychological & Social \\
\hline $\begin{array}{l}\text { Predisposing } \\
\text { (early) }\end{array}$ & $\begin{array}{l}\text { Family history } \\
\text { of depression } \\
\text { (mother and } \\
\text { sister) }\end{array}$ & $\begin{array}{l}\text { Anxious } \\
\text { personality, } \\
\text { previous } \\
\text { suicidal } \\
\text { thoughts during } \\
\text { stressful periods }\end{array}$ & $\begin{array}{l}\text { Strained } \\
\text { family } \\
\text { relationship } \\
\text { with little } \\
\text { support }\end{array}$ \\
\hline $\begin{array}{l}\text { Precipitating } \\
\text { (acute) }\end{array}$ & $\begin{array}{l}\text { Heightened } \\
\text { vigilance, } \\
\text { physical signs } \\
\text { of anxiety } \\
\text { like tremors } \\
\text { and loss of } \\
\text { appetite }\end{array}$ & $\begin{array}{l}\text { Military } \\
\text { discipline } \\
\text { meted out by } \\
\text { superior after a } \\
\text { mistake at work } \\
\text { resulting in } \\
\text { worries }\end{array}$ & $\begin{array}{l}\text { Being } \\
\text { placed in an } \\
\text { unfamiliar, } \\
\text { rigid military } \\
\text { environment }\end{array}$ \\
\hline \multirow[t]{2}{*}{$\begin{array}{l}\text { Perpetuating } \\
\text { (ongoing) }\end{array}$} & $\begin{array}{l}\text { Constant } \\
\text { fatigue from } \\
\text { insomnia }\end{array}$ & $\begin{array}{l}\text { Continued } \\
\text { perceived } \\
\text { inability to } \\
\text { perform tasks } \\
\text { correctly }\end{array}$ & $\begin{array}{l}\text { No close } \\
\text { friends/ } \\
\text { support within } \\
\text { his working } \\
\text { circle }\end{array}$ \\
\hline & $\begin{array}{l}\text { Poor appetite } \\
\text { and loss of } \\
\text { weight }\end{array}$ & $\begin{array}{l}\text { Persistent } \\
\text { fear of being } \\
\text { reprimanded by } \\
\text { superiors } \\
\text { Recurrent } \\
\text { intrusive } \\
\text { thoughts } \\
\text { keeping patient } \\
\text { awake }\end{array}$ & $\begin{array}{l}\text { Use of mobile } \\
\text { games to } \\
\text { combat } \\
\text { insomnia }\end{array}$ \\
\hline
\end{tabular}

In $\mathrm{Mr}$ T's case, the most distressing symptom of his psychiatric disorders was insomnia. Cognitive-behavioural therapy for insomnia (CBT-I) has been shown to be especially important in the treatment of insomnia and is still the mainstay of therapy. ${ }^{4}$ It is a multi-modal treatment combining the following techniques which can be taught by primary physicians.

General practitioners can introduce a sleep diary. We use the diary to track patients' sleeping patterns (identifying excessive nap times, going to bed too early or too late) and actions before bedtime that may prohibit sleep (i.e., stimulating activities like gaming in $\mathrm{Mr}$ T's case, clockwatching).

Sleep hygiene advice like avoidance of caffeine, nicotine, alcohol and heavy meal before bed is part of CBT-I. We also advise stimulus control therapy, where patients are taught to reserve their beds only for sleeping and not for other purposes like work.

Sleep restriction therapy involves a strict limit on the initial amount of time allowed lying on the bed. As the sleep efficiency increases, the patient increases their time in bed by $15-30$ minutes weekly until satisfactory sleep duration is achieved. However, this form of sleep deprivation should be avoided in NS personnel with high-risk vocations, especially those driving, handling dangerous ammunition, or diving.

Relapse prevention is also another part of CBT-I. Patients are taught ways to avoid insomnia relapse, such as not 
compensating for sleep loss the next day and re-initiating sleep restriction therapy for themselves should they lose sleep for a few days. Behavioural therapies that psychologists teach include progressive muscle relaxation techniques, deep breathing techniques, relaxing imagery and meditation.

This is often combined with cognitive therapy, where patients are taught to identify beliefs and ideas that induces their anxiety and insomnia, as well as how to rationalise out these incorrect thinking and alter their beliefs. ${ }^{5}$ Initiation of CBT for treatment of insomnia has also been shown to have a small to moderate effect on symptoms of anxiety as well in patients like $\mathrm{Mr} \mathrm{T}^{6}$

Encouragement of exercise, cessation of smoking, family members' involvement, avoidance of stressful situations when possible and supportive counselling are also important non-pharmacological therapies that the primary physicians can utilise in their daily practice for both insomnia and anxiety/depression treatment. ${ }^{7}$

\section{Pharmacological treatment}

Selective serotonin reuptake inhibitors (SSRIs) are the first-line pharmacological treatment for co-morbid GAD and depression. ${ }^{8}$ Choices of SSRIs include escitalopram, paroxetine, fluvoxamine, fluoxetine and sertraline. Comparison of SSRIs in the treatment of anxiety associated with major depression disorder (MDD) showed no difference in treatment efficacy. ${ }^{9}$ Primary physicians can choose SSRIs based on the patient profile, side-effect profile and patient tolerability, physician's drug familiarity and history of prior response to a particular SSRI in patient or family member. Serotonin norepinephrine reuptake inhibitors (SNRIs) like venlafaxine and duloxetine can also be used as a first-line treatment for co-morbid GAD and depression.

Some physicians have moved away from the use of benzodiazepines in the treatment of anxiety due to its side-effects and potential for abuse. In patients without complications of substance abuse, benzodiazepines may be considered as a bridging strategy for the rapid short-term relief of distressing insomnia until antidepressant and CBT-I take effect. However, there are no studies to support the long-term use of benzodiazepine in insomnia, hence limit the use to $2-4$ weeks. ${ }^{10}$ Although antidepressants like SSRI (selective serotonin reuptake inhibitors) may have sedative effects, clinicians should bear in mind antidepressants are still considered off-label use for insomnia treatment. There is no evidence for the use of antidepressants for the treatment of insomnia. ${ }^{11}$ However, in Mr T's case, the fluvoxamine initially prescribed was for GAD and depression indications. It was useful due to the patient's tendency to ruminate before sleep, and the SSRI reduces rumination. Clinicians should be mindful of the importance of tapering off BZD eventually when prescribing SSRI and BZD together.

\section{B. Keeping an open mind when seeing National Servicemen helps us remain cognizant for possible missed psychiatric disorders}

In Singapore, the latest large-scale population survey (Singapore Mental Health Study 2016) shows that the lifetime prevalence is 6.3 percent for major depressive disorder and 1.6 percent for GAD. The latter has a statistically significant increase since 2010. According to Parliament, from 2011 to 2014 , every year 500 men are exempted from N.S. due to mental health problems. ${ }^{12}$ Over the past five years, four percent of each NS cohort of 15,000 men has been downgraded for mental health issues. ${ }^{13}$ Currently, the National Service has a 24-hour counselling hotline for NSFs and in-camp counsellors and psychologists. While the NS has sufficient measures to detect and help pre-enlistees with mental health issues, some might still slip through the cracks and face difficulties during NS.

Stigmatisation surrounding malingering, as well as stigmatisation of mental illnesses, is a barrier for NS men in need of seeking help. Being exempted from N.S. on psychiatric grounds can cause self-stigmatisation and impact personal confidence. ${ }^{14}$ Unique to our local context, being a primarily conscripted National Service force, these men may have to explain their exemption to future schools and employers, and therefore reveal their mental illnesses.

This particular case study highlights the importance of remaining alert for possible psychiatric disorders when we see National Servicemen as patients outside of their camps. Primary physicians must avoid having a biased, clouded perspective when seeing National Service personnel with a possible underlying psychiatric disorder. ${ }^{15,16}$

As primary care physicians, we are the most likely first point of contact for patients with psychiatric issues. This is especially so for patients with mood and anxiety disorders as they are more likely to present with somatic complaints manifesting from psychiatric disorders. ${ }^{17}$

\section{Bridging care between National Service and public healthcare}

In this case study, we see a gap in the system that has to be addressed: A national serviceman straddling between two separate health systems (public and National Service) where medical records are not shared. This poses difficulty in cascading sensitive health information as oftentimes, the patient is the only medium for this. In this case, $\mathrm{Mr} \mathrm{T}$ took a passive role given the fear of stigmatisation by his superiors and colleagues. In addition, he had poor social support, and his current unfamiliar working and living environment in camp resulted in additional stressors.

Currently, for the NS serviceman, the NS healthcare, and its psychiatric care branch work closely with psychiatrists in tertiary hospitals in the management of their servicemen. Primary care physicians can also take an active role to facilitate better communication between healthcare services. We have contacted the psychiatric care branch and would 
Figure 3: Proposed pathway to manage N.S. personnel in the community

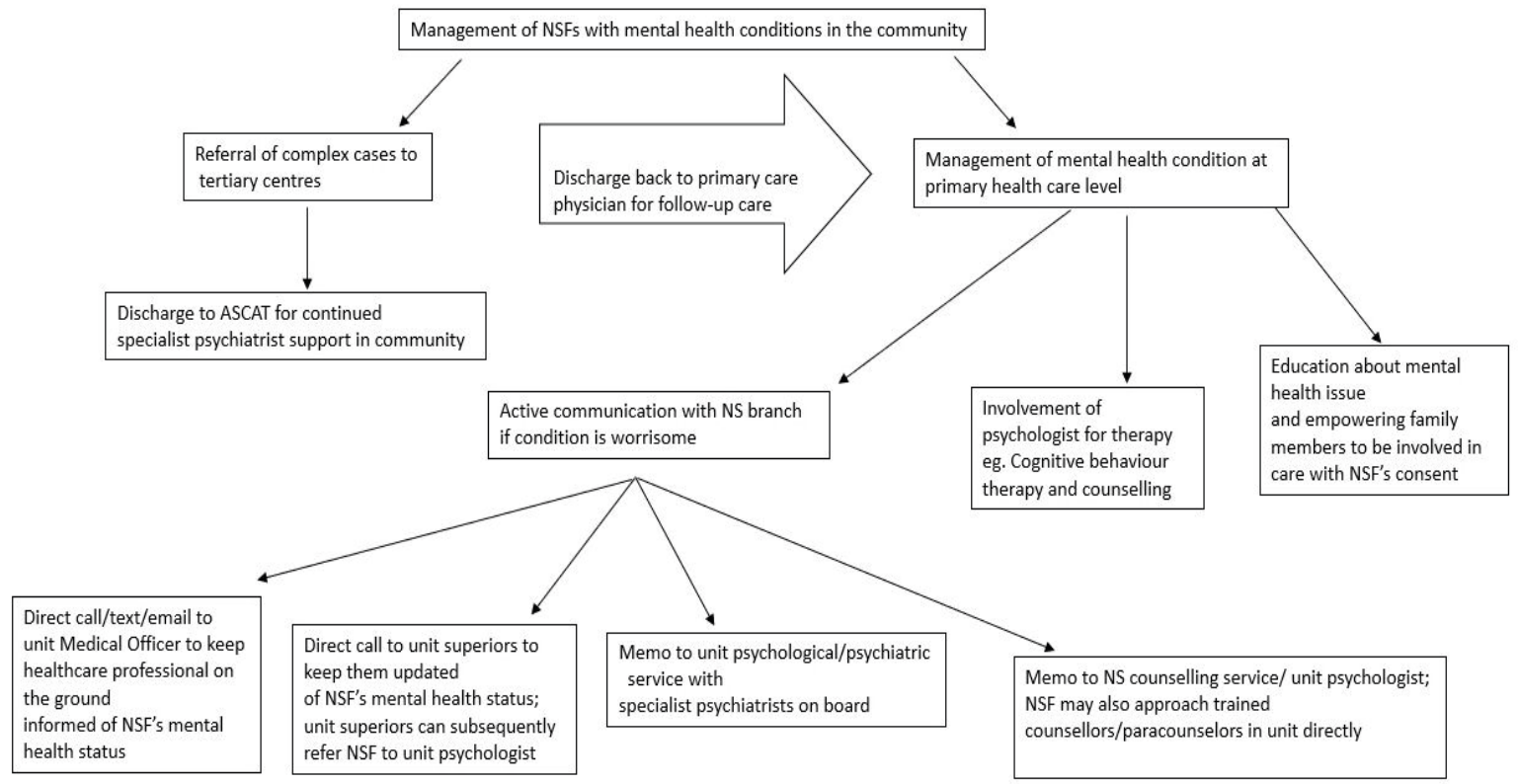

like to highlight to primary care providers who may be unaware of a suggested workflow that can be used to better communicate the condition and treatment plan for NS serviceman. This workflow is summarised in Figure 3.

We would also like to point out the mental health resources which are more readily available to NS conscript while awaiting camp doctor review and appropriate referrals.

1. 24-hour counselling hotline at 1800-278-0022

2. Unit para-counsellors are available in camp. We may advise the NS serviceman to approach the unit para-counsellors directly.

3. Unit psychologist are available in camp. We may advise the NS serviceman to produce a doctor's memo to the unit superior for a referral to a psychologist.

The waiting time to see a psychiatrist in the National Service health system may be longer due to patient load. Primary care providers are also reminded to consider an early referral to tertiary institutions for urgent cases that need specialist input.

\section{CLINICAL PRACTICE POINTERS}

1. Family physicians must be competent in dealing with NS patients with mental health conditions in the community and be aware of the resources available, including involving the mental health personnel from the National Service. They must be aware of the effects of stigmatisation and the side of caution when dealing with national servicemen who appear as "malingering".

2. Greater collaboration between the public and National Service health systems would allow for resource sharing, thus reducing healthcare costs and improve efficiency. This has to be balanced with maintaining patient confidentiality and security.

3. SSRIs and SNRIs are first-line pharmacotherapy for co-morbid generalised anxiety disorder and depression. Psychotherapies like CBT are equally important in the treatment of these psychiatric disorders and insomnia.

\section{ACKNOWLEDGEMENT}

We would like to acknowledge Dr Adrian Loh for his invaluable input.

\section{REFERENCES}

I. Subramaniam M, Abdin E, Vaingankar JA, Shafie S, Chua BY, Sambasivam R, Zhang YJ, Shahwan S, Chang S, Chua HC, Verma $\mathrm{S}$, James L, Kwok KW, Heng D, Chong SA. Tracking the mental health of a nation: prevalence and correlates of mental disorders in the second Singapore mental health study. Epidemiol Psychiatr Sci. 2019 Apr 5;29:e29. doi: 10.10I7/S2045796019000I79. PMID: 30947763.

2. van Balkom AJ, van Boeijen CA, Boeke AJ, van Oppen P, Kempe PT, van Dyck R. Comorbid depression, but not co-morbid anxiety disorders, predicts poor outcome in anxiety disorders. Depress Anxiety. 2008;25(5):408-I5. doi: 10.1002/da.20386. PMID: 17960642.

3. Belzer K, Schneier FR. Comorbidity of anxiety and depressive disorders: issues in conceptualisation, assessment, and treatment. J Psychiatr Pract. 2004 Sep; I0(5):296-306. doi: 10. I097/00 I 3 I 746200409000-00003. PMID: I536I744.

4. Buysse DJ. Insomnia. JAMA. 2013 Feb 20;309(7):706-16. doi: 10.1001/jama.2013.193. PMID: 23423416; PMCID: PMC3632369.

5. Siebern AT, Suh S, Nowakowski S. Non-pharmacological treatment of insomnia. Neurotherapeutics. 2012 Oct;9(4):717. 27. doi: 10.1007/sI33II-0I2-0I42-9. PMID: 22935989; PMCID: PMC3480569.

6. Belleville G, Cousineau H, Levrier K, St-Pierre-Delorme MÈ. Meta-analytic review of the impact of cognitive-behavior therapy 
for insomnia on concomitant anxiety. Clin Psychol Rev. 201I Jun;3 I(4):638-52. doi: I0.10I6/j.cpr.20II.02.004. Epub 20II Feb I7. PMID: 2 I 482322.

7. Kwek, T., 2019.Anxiety Disorders - Assessment and Management in General Practice. The Singapore Family Physician, 45(5), pp.6-12. doi: I0.3359|/sfp.45.5.ul

8. Coplan JD, Aaronson CJ, Panthangi V, Kim Y. Treating co-morbid anxiety and depression: Psychosocial and pharmacological approaches. World J Psychiatry. 2015 Dec 22;5(4):366-78. doi: 10.5498/wjp.v5.i4.366. PMID: 26740928; PMCID: PMC4694550.

9. Thaler KJ, Morgan LC, Van Noord M, Gaynes BN, Hansen RA, Lux LJ, Krebs EE, Lohr KN, Gartlehner G. Comparative effectiveness of second-generation antidepressants for accompanying anxiety, insomnia, and pain in depressed patients: A systematic review. Depression and anxiety. 2012 Jun;29(6):495-505.

10. Guina J, Merrill B. Benzodiazepines I: Upping the Care on Downers: The Evidence of Risks, Benefits and Alternatives. J Clin Med. 2018 Jan 30;7(2): I7. doi: 10.3390/jcm70200I7. PMID: 2938573।; PMCID: PMC5852433.

II. Sateia MJ, Buysse DJ, Krystal AD, Neubauer DN, Heald JL. Clinical practice guideline for the pharmacologic treatment of chronic insomnia in adults: an American Academy of Sleep Medicine clinical practice guideline. Journal of Clinical Sleep Medicine. 2017 Feb I5; I3(2):307-49.

12. Au Y. Parliament: 500 men a year exempted from NS due to mental health problems [Internet]. The Straits Times, 2014 May 29. Available from: https://www.straitstimes.com/singapore/ parliament-500-men-a-year-exempted-from-ns-due-to-mentalhealth-problems
13. Mahmud AH. Enough help for servicemen with mental health issues, experts say, but some still find NS a challenge [Internet] CNA, 2018 September 15. Available from: https://www. channelnewsasia.com/news/singapore/ns-mental-health-issuesnsmen-servicemen-106367/2

14. Greene-Shortridge TM, Britt TW, Castro CA.The stigma of mental health problems in the military. Mil Med. 2007 Feb; 172(2):157-6I. doi: 10.7205/milmed. 172.2.157. PMID: 17357770.

15. Yuan Q, Picco L, Chang S, Abdin E, Chua BY, Ong S, Yow KL, Chong SA, Subramaniam M. Attitudes to mental illness among mental health professionals in Singapore and comparisons with the general population. PLoS One. 2017 Nov 16;12(II):e0I87593. doi: 10.1371/journal.pone.0187593. PMID: 29|45419; PMCID: PMC5690645.

16. Subramaniam M, Abdin E, Picco L, Pang S, Shafie S, Vaingankar JA, Kwok KW, Verma K, Chong SA. Stigma towards people with mental disorders and its components - a perspective from multiethnic Singapore. Epidemiol Psychiatr Sci. 2017 Aug;26(4):37I382. doi: I0.1017/S20457960I6000I59. Epub 2016 Mar 28. PMID: 270I87I5; PMCID: PMC564766I.

17. Jeyagurunathan A, Abdin E, Shafie S, Wang P, Chang S, Ong HL, Abdul Rahman RF, Sagayadevan V, Samari E, Chua YC, Vaingankar JA. Pathways to care among psychiatric outpatients in a tertiary mental health institution in Singapore. International Journal of Social Psychiatry. 2018 Sep; 64(6):554-62. 